\title{
Special aspects of water use in Persian gardens
}

\author{
Albert FEKETE, Reza HAIDARI \\ Department of Garden Art and Landscape Techniques, \\ Faculty of Landscape Architecture, Corvinus University of Budapest, \\ email: albert.fekete@uni-corvinus.hu,reza.haidari@uni-corvinus.hu
}

Manuscript received April 30, 2015; revised May 30, 2015; accepted July 15, 2015

\begin{abstract}
The Persian garden is one of the most characteristic and notable element in the Iranian landscape. Considering Iran's hot and dry climate along with water deficit for plantation, it becomes noticeable how important the art of making gardens is to Iranians.

Water is one of the most crucial elements in the Persian garden, and we can state that gardens would be meaningless without it. Garden applications use water with its various abilities such as life, brightness, cleanliness, light, inertia, and motion, which bring forward numerous feelings in the human soul and enhance mental comfort. Also, its various running structures, such as basins, streams, water creeks, and fountains, provide mental comfort and technical functions.
\end{abstract}

Keywords: water system, water feature, decorative elements, functional role

\section{Introduction}

Among different natural elements, water is one of the most important elements, and it usually influences the other natural factors. Water has a deep relationship with the environment. Fluidity and flexibility make water a life-giving substance. Water offers playful musicality when moving, contemplative reflection when still. The fluidity of water represents the transparency of space and the unity of the garden. Most Iranian gardens are located in a semi-desert or desert inappropriately for such landscapes: hot and dry weather in the summer season, cold and dry weather in the winter, with very low precipitation (5-25 $\mathrm{mm}$ a year).

Donald Wilber wrote in his "Persian Gardens and Garden Pavilions" that the most important reasons for considering the Persian garden as "paradisian sites" are their rich water systems and luxuriant vegetation in an environment characterized by extremely hot weather and arid deserts in Iran. Therefore, a garden is a representation 
of paradise and it has held a sacred position in Persian beliefs. Accordingly, a garden is really important in religious trainings before and after Islam [12].

Water has always been deemed valuable in Iran since it was known as the omen of light and purity in ancient Persia. Water running in the four corners of Iranian gardens assimilates the four streams of water in the paradise [2]. In Iran, garden design is water design; Iranian enthusiasm for water has led to its use in various forms such as gardens, the quadrilateral scheme, brooks, low-slope, and winding stream to make the air cool, pleasant, and fresh.

\section{Materials and methods}

The present paper aims to investigate the importance of the main decorative water features such as pools, fountains, channels, and waterfalls, considering the functional roles of water use in Iranian gardens, with selected examples: by means of a descriptive approach, based on documents, literature review, and library studies of the various stylistics and aesthetics of water in Iranian gardens.

\section{Results and discussions}

Veneration and sanctification of water: Water as symbol of purity in Iran has always been an omen of cleanliness and brightness and it was highly valued in ancient Persia. Respect and sainthood attributed to water are deeply rooted in Iran. Anahita, the goddess of water, has always been present in the Iranian beliefs and the invigorating water is divided into four parts in its origin to create a paradise in the heart of the desert [10]. ${ }^{1}$

Source of water in Persian gardens: In most cases, Iranian garden ducts and natural springs have been the main sources of water supply in the gardens; the amount of water, its management and distribution done accurately and carefully have determined the garden's area. How to irrigate a garden - which is directly associated with the type of the land - is important wherever an Iranian garden is concerned.

Iran and the Iranians' interest in applying water in the garden is manifested in the fact that it has always been made to flow in different ways through the garden, enhancing its appeal and elegance [11].

\footnotetext{
${ }^{1}$ Anāhiti, also called Anāhitā: ancient Iranian goddess of royalty, war, and fertility; she is particularly associated with the last one. Possibly of Mesopotamian origin, her cult was made prominent by Artaxerxes II, and statues and temples were set up in her honour throughout the Persian Empire. In the Avesta, she is called Ardvī Sūrā Anāhitā ("Damp, Strong, and Untainted"); this seems to be an amalgam of two originally separate deities. In Greece, Anāhiti was identified with Athena and Artemis (Encyclopedia Britannica, 2010).
} 
In dry and hot parts of Iran, where surface water could not be counted with, Iranian people tried extracting and flowing hidden water in the layers of the ground through to the subterranean channels. Qanats lead water from mountains to villages and fields. This system supplies underground water through a series of shafts that use gravity to bring water to the surface (Fig. 1).

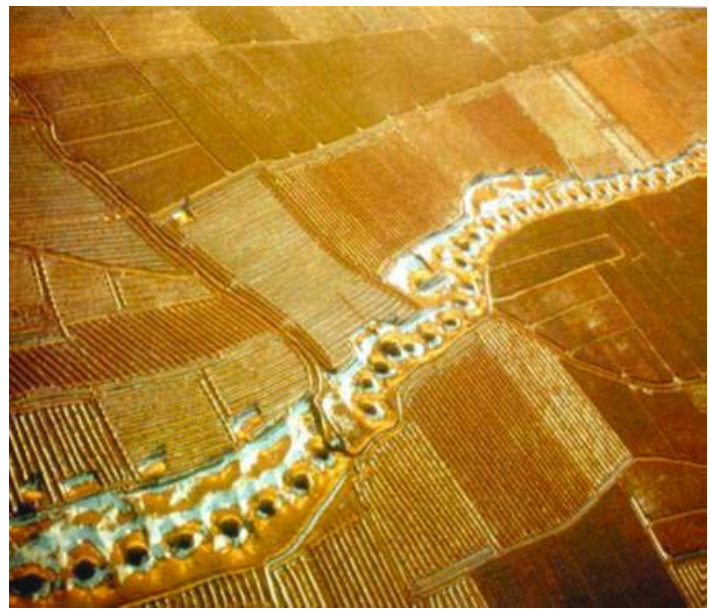

Figure 1. Aerial view of a qanat passing underground, located near Yazd [7]

Water supply in Persian gardens: There are clear relationships between the geometry, the layout of the gardens, and water supplying networks. The water affects geometry and axial composition, which is the channel's network directed to the geometrical formation of the garden. There is a classification into four parts for the needs of a water supplying network that shows that the garden geometry is based on the layout of the gardens. The geometry is created by the water supplying system and the needs are caused by the logic of water which matches well with the water supplying networks [5]. The Iranian garden as a whole cannot be visualized without water. The more water is available, the greater the role it plays in the garden landscape design. When water resources are abundant, the main construction of the gardens is moved to the nearest water source [8].

In this case, we can refer to the Farahabad garden ${ }^{2}$ in Isfahan and the Shah-Guli garden $^{3}$ in Tabriz - these are the good examples of pavilions located inside the pond.

\footnotetext{
2 Isfahan's Farahabad Garden was considered one of the most important historic gardens of Iran, despite its short life. Construction of the garden began in 1697 AD. An island was created in the middle of the lake and to the north, beyond which there was a palace, a narrow path connecting the island to the garden.

${ }^{3}$ The Shah-Guli (Royal Basin), one of the few gardens still remaining in Tabriz, was built in 1785 or possibly earlier. Tabriz is the capital of East Azerbaijan province.
} 
The main role of watering in the Persian garden: There are two main roles of watering in the Persian garden: functional and decorative.

Functional aspect of water: Irrigation is a major functional aspect of water in the Persian garden, and water used for cleaning purposes as well. Dividing the garden into a square or a rectangular shape, and using straight lines, make the irrigating of the garden easy - resulting in less wasted water and a timeless design that still works. Water from an aqueduct, a reservoir, or water-lifting device would enter the channels and be distributed through the quadrants. Water flooded each quadrant long enough for plant roots to be reached. Access was allowed or denied through opening or blocking entrance points with mud or stones.

Decorative aspect of water: The Persian garden features water for various decorative aspects, such as jets, fountains, pools, channels, and waterfalls, in order to get better water volume and symphonies. The qualities of water afford a range of opportunities in gardens. Pools that contain fish or ducks encourage plant growth, each of these elements contributing to a subtle movement of the water. Tanks or channels with fountains are eye-catching and lure the ears; besides spray action, the drops hitting the water surface provide pleasing sounds and rippling movements. The water's constantly changing behaviour offers contrast to the fixed elements of the garden: walls, footpaths, and statues. As water keeps moving, its circulation affects the air, cooling and moistening it. Playing in the sunlight, the falling water drops add a light-splitting dimension. The sound of falling or moving water alters other sounds, blocking or transforming them. Still water offers a distinct silence.

Directed water can produce particular effects, such as the plane that forms horizontally or vertically -, when water is forced through specific-sized openings. Water can slide silently, fall noisily, tumble gracefully, or splat messily. Thus, the water's effect on the quality of the environment is inestimable [6].

Jets, fountains. Water jets had places in indoor and outdoor pools. They spout water vertically with the effect of constructing a fountain by natural pressure. For example, the Hazar Jarib garden in Isfahan, created in the Safavid period, is served by five hundred jets. Lead pipes fed the jets. When the fountains are located in the main basin, they are the symbol of natural springs with a show of dancing water and pleasant sounds. Technology helped in - such as the nozzle design invented to spray the water in a variety of patterns that cooled the air and emitted distinctive sounds. Fountains became fixtures of Persian gardens [3].

Pools. Pools carry great importance in Persian gardens. Not for drinking, this water is in reserve for watering the garden, also with a cooling purpose, mirroring and settling dust on walkways and terraces. Pools vary in size and shape. The typical shapes were rectangular, square, circular, octagonal, and lobed or cross, and sometimes the size of the pool is related to the location and height of the building. Deep pools tend to be straight-sided. Basins are shallow and the walls of the pool are dark to reflect the building properly. Therefore, the walls of a pool are covered 
by granite or dark marbles. Pirnia, the father of Iranian traditional architecture, wrote that the pool wall is higher than the pool itself in Persian construction and a gutter is built in it in order for the extra water to escape [9]. This method was created by Persian architectures. Water overflows when the water source is entirely filled, resulting in an apparently endless pool, if viewed closely. The pools are typically situated along the garden's long axis; they sit at right angles to larger areas. We can say that reflection is one of the main features of a pool in the Persian garden as it creates a special visual effect on the water surface; when pools appeared within pavilions, they were there to reflect ornately decorated ceilings. Sky reflecting on still water surfaces brings light and an illusion of space and it is very shiny. For instance, the water views of the Dolat Abad garden ${ }^{4}$ in Yazd and Chehelsoton Garden ${ }^{5}$ in Isfahan are exactly along the main axis and their dimensions match those of the buildings to completely reflect the picture.

Channels. Water motion renders a garden transiency, a sense of novelty as well as freshness. Water originally flowed through Persian gardens in narrow and shallow channels; broad expanses of paving extended to both sides of the channel are covered by brick or stone. The evolution of design has enabled these channels to become wider, changing how water was used in the structure. Channels are used for irrigation and decorative roles, the zigzag or wave patterns decoration giving the illusion of water movement. Also, sin-e kabkis have marbles, which are carved and have some inscriptions on their surfaces (mostly their inscriptions resemble fish scales), and they are used where water flows through channels in or out of the basins and pools. A linear water channel plays an important role in arranging the garden space, and this straight channel line acts as a symbol of infinity in the garden. The fluidity-flux could be a semiological interpretation of the river/creek. It is constantly changing. It is never still and draws along, dissolving whatever it finds in its course. [1]

Waterfalls. In the main axes, water flows from one floor to the next floor when gardens are constructed on a slope. Iranians tried to use waterfalls to show the vertical surface of the water with the sound of water. By changing the levels at which water moved, they developed fountains capable of sending a directed cascade of water. The Shahzadeh Mahan garden ${ }^{6}$ in Kerman is the most beautiful example of using steep slopes to make waterfalls.

\footnotetext{
${ }^{4}$ The Dolat Abad garden is located in the heart of the Iranian desert provinces of Yazd. It was built in the period of 1748-1799 and its design is one of the most unique and innovative of official Iranian gardens.

${ }^{5}$ The Chehelsoton garden is located in Isfahan Province; it was built in 1647, forming an approximate shape of a square; the main layout of the garden is along the three East-West axes.

${ }^{6}$ The Shahzadeh garden is located in a vast desert, on the slope of the Jupar Mountain, where water flows down to irrigate the agricultural land of the Qarieh Region of Mahan, the provinces of Kerman. The garden was built in ca. 1850 and was extended in ca. 1870 .
} 
Table 1. Aesthetic and functional aspect of water in the Persian gardens

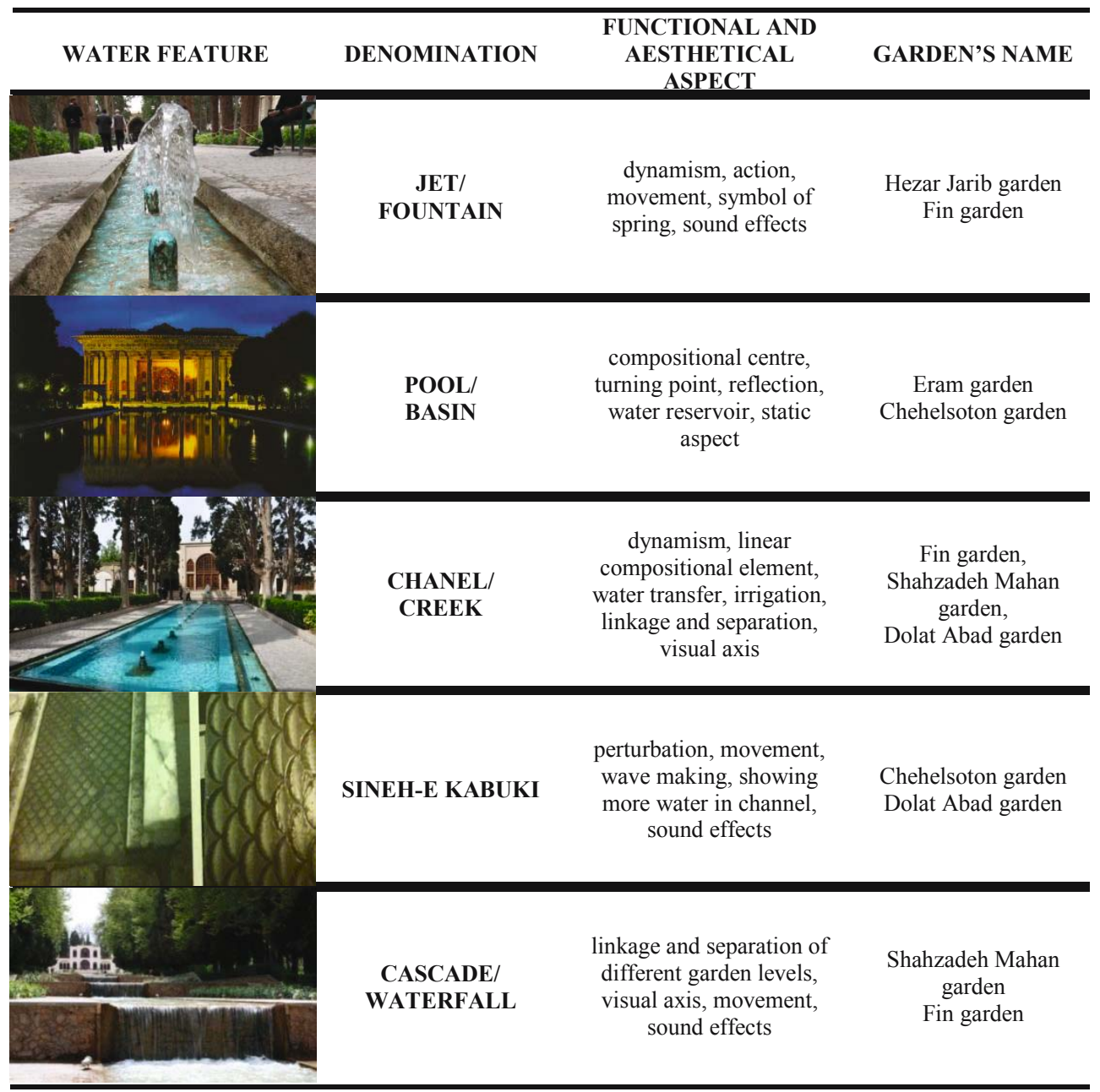

\section{Conclusion}

Water, an archetypal symbolic element of life, was linked with numerous beliefs for the Persians, and thanks to its magical power it occupied a central place in the garden as well. Water in the Persian garden used decoration and irrigating systems, always opting for the simplest way, from a short distance so that a minimum of water is wasted. In accordance with the garden's geometrical shape, the water divided the garden into a square or rectangle so that people could irrigate easily. Water motion through channels, reflecting in pools, spraying from jets or 
fountains, dripping or tinkling or lapping, presented functional and decorative elements in gardens - thus permeating them with meanings such as transiency, sense of novelty, or the concept of freshness with different temperatures inside the garden. The life-giving properties of the source, the fertile character of the garden that surrounds it and the cool feeling it emits, the water are personified by a goddess. Taking the arid Iranian climate into consideration, water sounds rushing, sloshing, and splashing - make people feel like entering the paradise to hear different water sounds, colours, waves, and shapes.

\section{References}

[1] Aidoni, Sofia (2000), Apple of discord, flower of good. In: On water in Byzantinum. Hellenic Ministry of Culture, Directorate of Byzantine and Postbyzantine Monuments, pp. 16-22.

[2] Ansari, M., Mahmoudinejad, H. (2007), Bagh-e Irani, Tamsili az Behesht [Iranian Garden, Allegory of Eden]. Journal of Fine Arts 29, 39-48.

[3] Brookes, J. (1987), Gardens of paradise: the history and design of the great Islamic gardens. New Amsterdam, New York.

[4] Diagram of a qanat system. http://ikiu-watereng.blogfa.com/post-60.aspx (accessed on: $15^{\text {th }}$ January 2015).

[5] Haghshenas, A. (2014), The importance of water bodies and structures in the Persian garden architecture. Vestnik MGSU 4. C. 29-36.

[6] Kalantari, A. (2011), Persian paradise gardens: history, elements, influences. Master Thesis. University of Southern California.

[7] Khansari, M., Moghtader, M. R., Yavari, M. (2004), The Persian garden: echoes of paradise. Mage Publishers, Tehran.

[8] Mansouri, S. A. (2005), An introduction to the aesthetics of the Iranian garden. Journal of Bagh-I-Nazar 1(3), 58-63.

[9] Pirnia A. (2008), Persian garden. Journal of Abadi 15, p. 56.

[10] Shahidi, M. Sh., Bemanian, M. R., Almasifar, N., Okhovat, H. (2010), A study on cultural and environmental basics at formal elements of Persian gardens (before \& after Islam). Asian Culture and History 2(2).

[11] Tajaddini, L. (2010), Review of the characteristics of Mahan Garden: one type of Persian gardens. World Academy of Science, Engineering and Technology 80.

[12] Wilber, D. N. (1962), Persian gardens and garden pavilions. First edition, Tokyo, C. E. Tuttle Co., p. 52. 